\title{
Imigrante em Madiã (Ex 2,15c-22) Traços característicos do personagem Moisés
}

\author{
Immigrant in Midian (Ex 2,15c-22) \\ Characteristic traits of the personage of Moses
}

Matthias Grenzer ${ }^{l}$

\section{Resumo}

As duas narrativas paralelas em Ex 2,11-22 apresentam Moisés, agora adulto, antes de sua vocação, por parte de Deus, de conduzir o povo dos oprimidos para fora da sociedade faraônica do Egito. Neste artigo, faz-se um estudo exegético da segunda narrativa (Ex 2,15c-22). A atenção se dirige aqui, de um modo especial, à descrição dos traços marcantes do personagem Moisés, visto que, ao escutar ou ler uma narrativa, o ouvinte-leitor atém-se particularmente ao conjunto dos personagens, os quais podem se tornar simpáticos ou antipáticos e, portanto, modelos de comportamento a serem seguidos ou não. Além disso, serão estudados os demais elementos constitutivos da narrativa, como os geográficos e os histórico-arqueológicos (Madiã), permitindo, assim, que se perceba melhor o contexto cronológico do mundo narrado. Serão, támbém, estudados os detalhes da trama e o modo como a voz do narrador se entrelaça com os discursos diretos dos personagens participantes da narrativa. Enfim, espera-se que, descobrindo os pormenores da composição poética da narrativa, se possa compreender mais profundamente a reflexão teológica subjacente a ela.

Palavras-chave: Bíblia; êxodo; Moisés; personagem; Madiã.

\footnotetext{
${ }^{1}$ Esta pesquisa foi apresentada no II Colóquio do Grupo de Pesquisa DIPRAI, o qual ocorreu durante os dias 13 a 15 de outubro de 2014 na UFRJ.
} 


\begin{abstract}
The two parallel narratives in Exod. 2:11-22 present the adult Moses before he receives his God-given vocation to lead the oppressed people out of pharonic society of Egypt. This article presents an exegetical study of the second narrative (Exod 2:15c-22). Special attention is given here to the marked characteristics of the personage of Moses in order to see whether the hearerreader, upon hearing/reading the story, will be sympathetic or have antipathy and whether the personages will be models of behavior to be followed or not. Also to be studied are the other elements which constitute the narrative, such as geography and historical-archeological issues (Midian), which allow for a better understanding of the chronological context of the narrative world. Additionally, the details of the plot and how the voice of the narrator intertwines with the directs discourses of the narrative's participants. Finally, it is hoped that discovering the narrative's poetic details make possible a more profound theological reflection which underlies the story.
\end{abstract}

Keywords: Bible; Exodus; Moses; character; Midian.

\title{
Introdução
}

Na história do êxodo, narrada nos últimos quatro livros do Pentateuco (Ex-Dt), o personagem Moisés - já crescido, ou seja, adulto (Ex 2,11b) - é apresentado duas vezes ao ouvinte-leitor, antes que se narre sua vocação por parte de Deus (Ex 3,1-4,17; 6,2-13). Na primeira cena, Moisés defende um hebreu agredido por um egípcio, ferindo este último mortalmente (Ex 2,11-15b). Em consequência disso, perseguido pelo faraó, Moisés se vê obrigado a fugir do Egito, terra na qual nasceu como hebreu. ${ }^{2}$ Logo em seguida, de forma paralela a este primeiro episódio, outro relato narrativo reapresenta Moisés. Novamente, este último é retratado como quem age em favor de quem está sendo agredido (Ex 2,15c-22). Dessa vez, porém, a cena ocorre na terra de Madiã.

$\mathrm{O}$ esforço de compreender o episódio artisticamente composto de Ex 2,15c-22 envolve estudos filológicos, narrativo-estilísticos e histórico-teológicos, conforme a metodologia das ciências bíblicas. A pesquisa aqui exposta se interessa, de um modo especial, pela presença intensa e pelos traços consti-

${ }^{2}$ Cf. GRENZER, Matthias. "Decidido a defender o oprimido (Ex 2,11-15c)". In: Matthias Grenzer, O projeto do êxodo. 2. ed. São Paulo: Paulinas, 2007, pp. 33-47. 
tutivos do personagem central na narrativa, Moisés. Logo após as duas cenas nas quais este último se arrisca em defesa aparentemente legítima de terceiros (Ex 2,11-22), narra-se como o SENHOR, Deus de Israel, ouvindo o grito dos hebreus (Ex 2,23-25), escolhe Moisés para lhe confiar a tarefa de conduzir o povo dos oprimidos para fora da sociedade que os oprime (Ex 3,1-4,17). Com isso, o ouvinte-leitor provavelmente se perguntará: por que Moisés? Ou melhor: o que caracteriza, de fato, o personagem considerado no Pentateuco como o profeta mais proeminente que Israel viu (Dt 34,10)? Para achar uma primeira resposta a tais questões, é preciso reler as cenas de Ex 2,11-22. Mais tarde, a própria continuação da história do êxodo poderá realçar, de diversas formas, como a escolha de Moisés foi acertada.

Neste momento, portanto, o enfoque recai sobre o "personagem". Afinal, "os personagens podem transmitir muito bem o que há de importante e precioso na narrativa, porque comumente ocupam de forma central a atenção" do ouvinte-leitor; ou seja, "sua história e personalidade provocam, no leitor ou na leitora, mais interesse do que todas as outras partes da narrativa, como, por exemplo, explicações, informações de fundo etc". ${ }^{3}$ Com isso, percebe-se que a técnica narrativa ligada à apresentação dos personagens ganha maior relevância no processo de construir, junto ao ouvinte-leitor, determinada reflexão teológica, sendo que "é através das figuras e da caracterização delas que a narrativa recebe sua coerência interna e coloração". ${ }^{4}$ Existe uma relação entre "narratologia e pragmática textual", no sentido de os personagens, com seus traços característicos, representarem valores positivos ou negativos e serem modelos de comportamento, sendo que estes podem ser simpáticos ou antipáticos ao ouvinte-leitor, influenciando seu pensamento e suas decisões. ${ }^{5}$

\section{Tradução e estrutura literária}

Seja apresentada, em primeiro lugar, uma tradução do texto bíblico originalmente composto em hebraico (Ex 2,15c-22), tendo como fonte a quarta edição

\footnotetext{
${ }^{3}$ BAR-EFRAT, Shimon. Wie die Bibel erzählt. Alttestamentliche Texte als literarische Kunstwerke verstehen. Gütersloh: Gütersloher Verlagshaus, 2006, p. 57.

${ }^{4}$ UTZSCHNEIDER, Helmut; NITSCHE, Stefan Ark. Arbeitsbuch Literaturwissenschaftliche Bibelauslegung. Eine Methodenlehre zur Exegese des Alten Testaments. 4. ed. Gütersloh: Gütersloher Verlagshaus, 2014, p. 158.

${ }^{5}$ DORMEYER, Detlev. Narratologie und Pragmatik. Ein Zwischenbericht. In: Biblische Zeitschrift 58 (2014), p. 259.
} 
crítica da Biblia Hebraica Stuttgartensia. ${ }^{6}$ Para destacar o objeto de estudo deste artigo, as citações bíblicas diretas encontram-se grafadas em itálico.

v. 15c Moisés fugiu do faraó

v. 15d e foi morar na terra de Madiã.

v. 15e Sentou-se junto ao poço.

v. 16a Ora, vieram as sete filhas do sacerdote de Madiã.

v. 16b Tiraram água

v. 16c e encheram os bebedouros,

v. 16d a fim de fazer beber o gado menor do pai delas.

v. 17a No entanto, vieram os pastores

v. $17 \mathrm{~b}$ e os expulsarem.

v. 17c Então Moisés se ergueu,

v. $17 \mathrm{~d}$ as salvou

v. 17e efez seu gado menor beber.

v. 18a Chegaram a seu pai Raguel,

v. $18 \mathrm{~b}$ que disse:

v. 18c "Por que hoje vos apressastes em chegar?"

v. 19a Disseram:

v. 19b "Um egípcio nos libertou da mão dos pastores.

v. 19c Também tirou água para nós

v. 19d e fez o gado menor beber!"

v. 20a Então disse a suas filhas:

v. $20 \mathrm{~b} \quad$ "Onde está ele?

v. 20c Por que isso?

v. 20d Abandonastes o homem?

v. 20e Chamai-o,

v. 20f para que coma pão!"

v. 21a Moisés decidiu morar com o homem,

v. 21b o qual deu sua filha Séfora a Moisés.

v. 22a E deu um filho à luz.

v. 22b Chamou-o de Gérson,

v. 22c porque disse:

v. 22d "Tornei-me um imigrante em terra estrangeira!"

${ }^{6}$ ELLIGER, Karl; RUDOLPH, Wilhelm (Eds.). Biblia Hebraica Stuttgartensia. 4. ed. Stuttgart: Deutsche Bibelgesellschaft, 1997. 
O início da narrativa se encontra realçado por uma dupla mudança. Há, primeiramente, uma alteração referente ao sujeito que age. Enquanto em Ex $2,15 \mathrm{~b}$ a ação ainda pertence ao faraó, sendo que este procura matar Moisés, no v. 15c é Moisés quem foge. Aliás, a repetição do nome Moisés - ora na posição de objeto (Ex 2,15b), ora no lugar de sujeito (v. 15c) - permite, desde o início, que o ouvinte-leitor se concentre no personagem que irá ganhar centralidade no episódio a ser narrado. No segundo momento, ligado ao personagem Moisés, ocorre uma mudança de local. Ao fugir, pois, do faraó (v. 15c), Moisés chega, vindo do Egito, à terra de Madiã (v. 15d). Essa mudança torna-se ainda mais chamativa, quando se observa que, até agora, a trama da história do êxodo se limitou ao ambiente geográfico do Egito (Ex 1,1-2,15c). Aliás, logo após o episódio apresentado em Ex 2,15c-22, o ouvinte-leitor voltará sua atenção aos filhos de Israel, sendo que estes ainda estão no Egito (Ex 2,23-25).

No que se refere ao conjunto da narrativa aqui estudada, este se divide em três partes. A primeira cena (v. 15c-17e), formada por doze meios-versículos ou segmentos, ocorre ao lado ou junto a um determinado poço na terra de Madiã (v. 15d-e). No texto hebraico, lê-se o poço, e não um poço. Participam diretamente dessa cena os personagens Moisés (v. 15c.17c), as sete filhas do sacerdote de Madiã (v. 16a), um grupo de pastores (v. 17a) e também o gado menor (v. 16d.17e) do pai (v. 16d) das filhas. A presença do gado menor como personagem pode ser observada na formulação do v. 17a-b. Narra-se que $o s$ pastores vieram e os expulsaram. Ou seja: o sufixo pronominal acrescentado ao verbo apresenta a forma da terceira pessoa do plural no masculino, que se refere ao gado menor. Quer dizer, eles - as filhas e o gado menor - foram expulsos pelos pastores. Contudo, pode-se interpretar também que os pastores queriam expulsar, junto com as filhas do sacerdote de Madiã, o próprio Moisés.

Na segunda cena (v. 18a-20c), o ouvinte-leitor acompanha um diálogo entre Raguel e as sete filhas dele, pois estas, do poço (v. 15e), voltaram a seu pai (v. 18a), tendo deixado para trás Moisés (v. 20c). Ocorre, portanto, uma mudança de local. No mais, prevalecem agora os discursos diretos (v. 18c.19b-d.20b-e), sendo que a voz do narrador se limita a introduzi-los (v. 18a-b.19a.20a).

A terceira cena (v. 21a-22d) junta Moisés ao sacerdote de Madiã e, em especial, à Séfora, uma das sete filhas, sendo que dessa união nasce o filho Gérson. Contudo, nesses versículos finais, "a narrativa se interessa apenas pelo resultado dos acontecimentos e o apresenta, sem ambiente cênico, em 
forma de uma notícia escassa de detalhes". ${ }^{7}$ No entanto, o final da narrativa ganha maior realce por apresentar um discurso direto de Moisés (v. 22d). É a única vez que esse personagem, tão central na trama da história do êxodo, fala no episódio. Isso, porém, não significa que não tenha centralidade na narrativa aqui estudada. Com exatamente sete ocorrências, a narrativa destaca a presença do futuro líder dos israelitas ora como Moisés (v. 15c.17c.21a.b), ora como egípcio (v. 19b), ora como homem (v. 20c) ou imigrante (v. 22d). No mais, toda a trama é provocada pelo comportamento dele.

O fim do episódio é bem marcado por se formar, através de duas expressões, uma inclusão que moldura toda a cena. Ocorre, pois, a repetição do termo terra (v. 15d.22d). Mais ainda: Madiã (v. 15d.16a) é descrita agora, pelo próprio Moisés, como terra estrangeira (v. 22d). No mais, o verbo hebraico traduzido aqui ora por morar ora por sentar-se, além de marcar duplamente o início do episódio (v. 15d.e), aparece uma terceira vez no final da narrativa (v. $21 \mathrm{a}){ }^{8}$

\section{Observações histórico-teológicas}

\subsection{Fugitivo (v. $15 \mathrm{c}-\mathrm{e})$}

A fuga do faraó leva Moisés à terra de Madiã. Como região, Madiã aparece, nas tradições da Bíblia Hebraica, cinquenta e nove vezes, sendo que, em dezoito delas, no Pentateuco (Gn 25,2.4; 36,35; Ex 2,15.16; 3,1; 4,19; 18,1; $\left.\mathrm{Nm} 22,4.7 ; 25,15.18 ; 31,3^{2 \times} .7 .8^{2 \times} .9\right)$. Além disso, há outras oito presenças do gentilício madianita(s), todas elas no Pentateuco (Gn 37,28.36; Nm 10,29; $25,6.14 .15 .17 ; 31,2)$. As pesquisas arqueológico-geográficas permitem hoje uma compreensão melhor da localização e história de Madiã.

"Geógrafos greco-romanos e árabes conhecem uma cidade chamada de Madiama/Madyan, a qual, segundo viajantes do tempo moderno e recentes pesquisas arqueológicas, precisa ser identificada com al-Bad', no leste do Golfo de Ácaba." "9 Há outros locais no extremo noroeste da península árabe, no território da atual Arábia Saudita, onde arqueólogos escavaram restos

\footnotetext{
${ }^{7}$ UTZSCHNEIDER, Helmut; OSWALD, Wolfgang. Exodus 1-15. Stuttgart: Kohlhammer, 2013, p. 99.

${ }^{8}$ Cf. DIETRICH, Walter; ARNET, Samuel (Eds.). Konzise und Aktualisierte Ausgabe des Hebräischen und Aramäischen Lexikons zum Alten Testament (Koehler \& Baumgartner). Leiden: Brill, 2013, pp. 230-231.

9 KNAUF, Ernst Axel. Midian. Untersuchungen zur Geschichte Palästinas und Nordarabiens am Ende des 2. Jahrtausends v. Chr. Wiesbaden: Otto Harrassowitz, 1988, p. 1.
} 
arquitetônicos e encontraram camadas de cerâmica que atestam a presença de colônias madianitas nos séculos XIII e XII a.C. Deduz-se, assim, que os madianitas tenham habitado uma região que se estendia até Tayyib al-Ism, no norte, e al-Qurayya, no leste. No oeste, o Mar Vermelho, ou seja, o Golfo de Ácaba, marcava o limite. Ali, Maqna era uma das colônias dos madianitas. No sul, existiam as colônias no Wadi 'Ainuna. ${ }^{10}$ Contudo, cerâmica madianita foi encontrada até o norte da península do Sinai, assim como em Gezer e Amã. "Trata-se de louça feita de fina argila amarela, com decoração bicolor, mostrando desenhos geométricos e representações figuradas." 11

Os madianitas praticavam uma agricultura com técnicas de irrigação, criando pequenas parcelas de terra em forma de terraços. ${ }^{12}$ Além disso, eram criadores de gado, em especial de camelos, sendo que, "no primeiro milênio a.C., Madiã, no noroeste da Arábia, se tornou uma região famosa pela criação de camelos", embora a prática já tenha começado "no segundo milênio a.C.". ${ }^{13}$ Aliás, "a domesticação do camelo - como animal de carga e fornecedor de carne, leite, lã e esterco - começara já no terceiro milênio a.C., em meio à cultura sedentária" ${ }^{14}$ Contudo, apenas com a descoberta de selas mais favoráveis ao uso do camelo como animal de montaria é que surge, no decorrer do primeiro milênio a.C., a possibilidade de aproveitar o camelo em ações bélicas. ${ }^{15}$ Quer dizer: imaginar os madianitas, descendentes de Abraão e Cetura (Gn 25,1-4), como guerreiros-assaltantes que, vindo do deserto, usam o camelo para seus ataques não é, historicamente, compatível com o período em que se localiza o evento do êxodo e, assim, com a trajetória de Moisés. Pelo contrário, conforme a narrativa aqui estudada, Moisés, em princípio, foi bem recebido pelos madianitas, embora logo tenha experimentado os conflitos existentes nessa sociedade.

Todavia, a ação de Moisés descrita nos primeiros três segmentos da narrativa (v. 15c-e) leva o ouvinte-leitor a imaginar que o futuro líder do povo dos oprimidos, junto a seu deslocamento, faz uma experiência de vida correspon-

\footnotetext{
${ }^{10}$ Ver o mapa em KNAUF, Midian, p. 2. Ver também a localização de Madiã In: Wolfgang Zwickel, Atlas bíblico. São Paulo: Paulinas, 2010, pp. 25.27.29.

${ }^{11}$ FRITZ, Volkmar. Die Entstehung Israels im 12. und 11. Jahrhundert v. Chr. Stuttgart: Kohlhammer, 1996, p. 176.

${ }^{12}$ Cf. KNAUF. Midian, p. 6.

${ }^{13}$ KNAUF. Midian, p. 14.

${ }^{14}$ KNAUF. Midian, p. 9.

${ }^{15}$ Cf. KNAUF. Midian, p. 10.
} 
dente à dinâmica do êxodo. Sua fuga do faraó, pois, antecede, de certa forma, a posterior saída do povo dos oprimidos da sociedade opressiva. Isso pode ser percebido no nível da linguagem quando, no momento do êxodo, será anunciado ao rei do Egito que o povo dos hebreus tem fugido (Ex 14,5), embora tal saída tenha sido autorizada pelo governante. Além disso, com sua fuga, Moisés, defensor da liberdade dos oprimidos, se torna semelhante a Balaão, o qual, mais tarde, irá precisar fugir de Balac, rei de Moab, por não amaldiçoar, como pedido por este último, o povo do êxodo, justamente por descobrir a atuação favorável de Deus a quem está caminhando rumo à liberdade, saindo, fisicamente, da sociedade opressiva.

Enfim, a fuga de Moisés tem sucesso. Ele consegue salvar sua vida da perseguição do faraó, algo que, de forma indireta, se torna um sinal para sua inocência em vista do ferimento mortal do egípcio (Ex 2,11-15b). Quem, pois, segundo o direito do antigo Israel, não mata de forma proposital, armando uma cilada, mas chega a ferir alguém mortalmente em autodefesa ou defesa de um terceiro, deve achar, por vontade de Deus, um lugar onde possa se refugiar (Ex 21,13). Mais ainda: Moisés encontra, em meio ao deserto, aquilo de que mais se precisa. Sentado junto a um poço (v. 15e), ele tem acesso à água (cf. v. 16b).

\subsection{Observador (v. 16a-17b)}

Sentado junto a um determinado poço (v. 15e), Moisés observa a chegada de sete mulheres jovens (v. 16a). São as filhas, aparentemente não casadas, do sacerdote de Madiã (v. 16a). Ao menos para Séfora, uma delas, isso é pressuposto, pois, no final da narrativa, ela é dada, por seu pai, a Moisés como esposa (v. 21b). Como filhas do sacerdote da região, de certa forma, as meninas pertencem a "uma família nobre". ${ }^{16}$ Isso, por sua vez, não é necessariamente do conhecimento Moisés. O ouvinte-leitor o sabe, porque o narrador lhe oferece tal informação. No mais, o fato de elas serem justamente sete é, no mínimo, curioso. Na cultura literária do antigo Israel, pois, este número reaparece em outras histórias bem-sucedidas e abençoadas por Deus, ao menos inicialmente: confira os sete filhos da mulher estéril (1Sm 2,50), os imaginados sete filhos de Rute (Rt 4,15) e os sete filhos gerados pela jerosolimita $(\operatorname{Jr} 15,9)$.

\footnotetext{
${ }^{16}$ FISCHER, Georg; MARKL, Dominik. Das Buch Exodus. Stuttgart: Katholisches Bibelwerk, 2009 , p. 40.
} 
Contudo, na narrativa aqui estudada, elas são especificamente sete filhas (v. 16a). Pelo que parece, não existem irmãos. Assim, elas realizam seu trabalho de pastoras sozinhas, cuidando do gado menor de seu pai (v. 16d). Por conta própria, tiram água do poço (v. 16b), enchem os bebedouros (v. 16c) e fazem beber os animais de seu pai (v. 16d). De certo, mulheres podiam e precisavam ser pastoras (ver Rebeca em Gn 24,15 e Raquel em Gn 29,9, assim como a amada em Ct 1,8). Isso fazia parte da vida cotidiana. Contudo, caso estivessem sozinhas, elas se encontravam indefesas e vulneráveis aos maus tratos de seus colegas homens (cf. Ct 1,7).

Justamente esse tipo de situação é presenciada por Moisés num determinado poço na terra de Madiã, quando se aproximam pastores homens (v. 17a) dispostos a expulsar as sete colegas-mulheres e o gado menor do pai delas (v. 17b). Há, portanto, uma situação em que um grupo de pessoas supostamente mais fortes quer "se beneficiar do resultado do trabalho realizado por outros". ${ }^{17}$ No entanto, Moisés está atento àquilo que, em geral, se torna desagradável aos olhos de quem se preocupa, de forma exclusiva, com seu bem-estar, imaginando que, em situações delicadas como essa, nada possa ser feito. Pelo contrário, Moisés se comove com o que vê. E, por manter-se ligado ao que observa, tem uma reação corajosa.

\subsection{Salvador e benfeitor (v. $17 \mathrm{c}-\mathrm{e})$}

No final da cena no poço, três segmentos apresentam ações do protagonista da narrativa. Após Moisés ter sido o sujeito dos três verbos no início da cena (cf. v. 15c-e), ele o é novamente no final (cf. v. 17c-e). Ocorre uma reação surpreendente. "Embora Moisés esteja sozinho contra uma maioria e apesar de se encontrar em terra estrangeira e já ter experimentado derrotas em dois casos semelhantes", exatamente ao defender um hebreu que estava sendo injustiçado por um egípcio (Ex 2,11) e outro hebreu agredido por um hebreu (Ex 2,13), "ele novamente se apresenta como quem é favorável aos oprimidos". ${ }^{18}$ Quer dizer, "o observador silencioso agora se torna atuante", erguendo-se (v. 17c) e salvando as filhas do sacerdote de Madiã (v. 17b). ${ }^{19}$

Com isso, Moisés se torna semelhante ao SENHOR, o qual, mais tarde, irá salvar Israel das mãos dos egípcios (Ex 14,30). Aliás, Israel sempre é

\footnotetext{
${ }^{17}$ FISCHER; MARKL. Das Buch Exodus, p. 41.

${ }^{18}$ FISCHER; MARKL. Das Buch Exodus, p. 41.

${ }^{19}$ UTZSCHNEIDER; OSWALD. Exodus 1-15, p. 99.
} 
convidado a compreender-se como povo salvo pelo SENHOR (Dt 33,29), consciente de que seu Deus está disposto a salvá-lo, sempre de novo, de seus inimigos (Nm 10,9; Dt 20,4). Afinal, cultiva-se a esperança de que o SENHOR, como Deus, se erga e salve aquele que, injustiçado por outros, grita a ele $(\mathrm{Sl} 3,8 ; 12,6 ; 76,10)$.

Contudo, Moisés não se limita à ação salvadora em favor de quem está sendo agredido (v. 19b), mas também é capaz de assumir o trabalho cotidiano do outro. É ele quem faz o gado menor das sete irmãs beber (v. 16d.17e), sendo necessário que tire também água para elas (v. 19c-d). Quer dizer, no início, ele apenas tinha observado as mulheres nesse seu trabalho (v. 16). Agora, porém, após elas terem sido agredidas pelos pastores, Moisés, no lugar delas, assume o trabalho que estavam realizando. Com isso, as sete filhas do sacerdote de Madiã podem descansar e contemplar um modelo alternativo de comportamento no que se refere aos homens. Talvez os pastores agressivos já tivessem dado a água tirada pelas colegas pastoras a seus animais, ou elas ainda não tivessem completado seu trabalho de puxar para cima a quantia suficiente de água. Em todo caso, é Moisés quem realiza agora o mesmo trabalho que as mulheres iriam realizar. Com isso, "vai para além das convenções da relação tradicional entre os gêneros", sendo que, "em vez de buscar uma vida cômoda, procura fazer-se útil". ${ }^{20}$ Com outras palavras, Moisés não somente defende as mulheres num momento delicado, mas também divide o trabalho cotidiano com elas, sobretudo após o desgaste delas por causa do conflito desnecessário com os pastores. Talvez seja algo bem natural. Contudo, ao agir contrariamente aos pastores violentos, Moisés se qualifica, aos olhos do pai das filhas, para um projeto de convivência mais amplo, como narra a segunda cena da narrativa.

\subsection{Libertador bem-vindo (v. 18a-20e)}

A segunda cena da narrativa aqui estudada ocorre na casa ou na tenda do pai das sete filhas e faz o ouvinte-leitor escutar um pequeno diálogo. Moisés não participa ativamente da conversa, mas ele é o assunto. O sacerdote de Madiã, chamado Raguel, é informado por suas filhas dos acontecimentos surpreendentes no poço.

Aparentemente, as filhas do sacerdote de Madiã sofriam, com frequência, agressões por parte de seus colegas pastores. Por isso, seu pai tem a

${ }^{20}$ FISCHER; MARKL. Das Buch Exodus, p. 42. 
impressão de que, nesse dia, elas demonstraram pressa em voltar para casa (v. 18). Mais tarde, o ouvinte-leitor se lembrará desse detalhe, quando os filhos de Israel deverão sair do Egito com pressa (cf. Ex 12,11). Contudo, Raguel quer saber por que isso aconteceu (v. 18c).

A pergunta do pai oferece às filhas a oportunidade de destacarem o que aconteceu de tão surpreendente. No caso, relatam primeiramente que um egípcio as libertou da mão dos pastores (v. 19b). Com isso, Moisés ganha, outra vez, semelhança com o SENHOR, Deus de Israel, que irá libertar seu povo da escravidão como também das tribulações no caminho rumo à terra prometida (cf. Ex 3,8; 5,23; 6,6; 12,27; 18,8.9.10; Dt 23,15). Quer dizer, como posteriormente durante a dinâmica do êxodo, também nesse caso a pressa feliz foi possibilitada por uma ação libertadora. Mais ainda, Moisés liberta as sete filhas do sacerdote de Madiã de acordo com sua experiência de ter sido liberto da espada do faraó (Ex 18,4). Aliás, nas tradições jurídicas do antigo Israel, imagina-se também a possibilidade de que, em determinado momento, uma mulher possa se aproximar para libertar seu marido de uma briga (Dt 25,11).

Talvez com certo humor, as filhas, "em seu relato, retratem a ação de Moisés mais fortemente do que ela foi apresentada na primeira cena". ${ }^{21}$ Ao descreverem a ação salvadora de Moisés (v. 17c-d) como libertação da mão dos pastores (v. 19b) repetindo o fato de Moisés ter feito o gado menor beber (v. 17e.19d), chamam a atenção de seu pai, sobretudo, para o fato de Moisés, descrito como egípcio (v. 19b), tê-las ajudado. Quer dizer, as filhas do sacerdote de Madiã ficaram impressionadas não somente por Moisés tê-las salvo da agressão dos pastores, mas também por ele gentilmente ter realizado o trabalho mais exigente: Também tirou, sim, tirou água para nós (v. 19c). Vale notar que, no texto hebraico, a raiz verbal tirar é repetida. Em geral, essa figura etimológica, formada pelo infinitivo absoluto e uma forma finita do mesmo verbo, dificilmente é traduzida para o português.

Enfim, Moisés está disposto a ajudar e, portanto, salvar e libertar, de forma gentil, aquele que, em princípio, fisicamente não tem a mesma força. Nesse caso, não importa se o homem é hebreu (Ex 2,6), egípcio (v. 19b) ou madianita. Os pastores, no caso, perderam sua chance. Moisés, por sua vez, "não busca uma vida cômoda, mas tenta ser útil onde vê necessidade e chance de ajudar". ${ }^{22}$

${ }^{21}$ UTZSCHNEIDER; OSWALD. Exodus 1-15, p. 99.

${ }^{22}$ FISCHER; MARKL. Das Buch Exodus, p. 42. 
É possível que as filhas, de forma encantadora, tenham ficado confusas com tanta gentileza, "tendo deixado para trás o estrangeiro, sem lhe agradecer". ${ }^{23}$ Talvez, porém, elas ajam assim por causa da formação que receberam ou dos costumes e da cultura da época. Não iriam invadir a privacidade do pai com alguém até então desconhecido, sem que houvesse um convite para isso. Contudo, Raguel - cujo nome significa companheiro de Deus ou Deus é companheiro - "reage imediatamente", sendo que, "de forma indireta", suas afirmações "fazem soar uma acusação", por mais que ela pareça ser apenas retórica: Onde está ele? (v. 20b); Por que isso? (v. 20c); Abandonastes o homem? (v. 20d). ${ }^{24}$ Em seguida, ele ordena que chamem o benfeitor solidário e gentil (v. 20e), a fim de que goze de sua hospitalidade, comendo pão (v. 20f). Ou seja, Moisés é bem-vindo por estar disposto a defender o mais fraco diante de agressores e por saber oferecer a ajuda de sua mão a quem estava acostumado com a mão de pastores grosseiros e violentos.

\subsection{Imigrante (v. 21a-22d)}

A hospitalidade de Raguel oferece a Moisés a oportunidade de integrar-se, de um modo mais permanente, na sociedade madianita. Em terra estrangeira, ofugitivo do Egito se torna imigrante (v. 22d).

De um lado, a notícia curta no final da narrativa apresenta tal processo imigratório como resultado da vontade de Moisés, sendo que este decide estabelecer-se ou morar com o homem (v. 21a), ou seja, junto ao sacerdote de Madiã. De outro lado, porém, é a hospitalidade de Raguel, cuja atitude é bem diferente se comparada à dos pastores, que possibilita a permanência de Moisés nessa região. O processo imigratório de Moisés é acelerado pelo fato de este último receber Séfora, uma das sete filhas do sacerdote de Madiã, como esposa (v. 21b). Além disso, Séfora, cujo nome significa "passarinho", lhe dá um filho (v. 22a). Com isso, o processo de estabelecimento de Moisés nas terras de Madiã (v. 15d) se transforma em enraizamento.

Não obstante, o nome do filho e sua interpretação por parte de Moisés indicam que a estada em Madiã não é definitiva. O nome hebraico Gérson (v. $22 \mathrm{~b}$ ) pode ser explicado de duas formas. De um lado, as primeiras três letras espelham as letras que formam a raiz verbal expulsar. Dessa forma, o nome

\footnotetext{
${ }^{23}$ UTZSCHNEIDER; OSWALD. Exodus 1-15, p. 99.

${ }^{24}$ FISCHER; MARKL. Das Buch Exodus, p. 41.
} 
"lembra a ajuda de Moisés para as filhas de Raguel", as quais estavam sendo expulsas pelos pastores (v. 17b). ${ }^{25}$. De outro lado, por sua vez, o nome Gérson pode ser interpretado como resultado da junção de duas palavras hebraicas, com o significado de "um imigrante ali". Dessa forma, Moisés, através de seu discurso direto no final da narrativa, parece atribuir certo sentido a sua permanência em Madiã, dizendo (v. 22c): Tornei-me um imigrante em terra estrangeira! (v. 22d; Ex 18,3). Quer dizer, apesar de todo o seu processo imigratório, Madiã continua sendo terra estrangeira. Assim, o ouvinte-leitor da narrativa tem a impressão de que se trate apenas de uma etapa temporal e provisória no caminho de Moisés. ${ }^{26}$

\section{Conclusão}

Após a leitura crítico-literária de Ex 2,15c-22, cabe aqui destacar os traços que a própria narrativa bíblica, de forma característica e marcante, atribui ao personagem Moisés.

Como fugitivo e imigrante em Madiã, Moisés experimenta que a saída da sociedade opressiva e a sobrevivência em terras novas, por mais que estas sejam estrangeiras, são possíveis. Moisés consegue estabelecer-se e morar num novo ambiente e sabe buscar sua sobrevivência material, encontrando água. Além disso, de forma surpreendente, consegue integrar-se em uma sociedade que não era sua, gozando da solidariedade e convivência íntima de pessoas até então desconhecidas, sendo que estas fazem o fugitivo experimentar o companheirismo de Deus.

Todo esse diálogo, por sua vez, se torna possível a partir de uma determinada atitude de Moisés. Em meio a um conflito violento, ele defende, de maneira desinteressada, quem está indefeso, sem se importar com sua própria segurança e eventuais tradições culturais ou costumes de gênero. Prevalece apenas sua sensibilidade em relação à justiça, de forma imparcial e constante. Além disso, Moisés sabe fazer-se útil, tornando-se um colaborador bem-vindo na realização dos trabalhos corriqueiros do dia a dia.

\footnotetext{
${ }^{25}$ UTZSCHNEIDER; OSWALD. Exodus 1-15, p. 100.

${ }^{26}$ Ao continuar a acompanhar a história do êxodo, será interessante para o ouvinte-leitor observar como o sogro de Moisés - ora chamado de Raguel (Ex 2,18; Nm 10,29), ora de Jetro (Ex 3,1; 4,18 2x; 18,1.2.5.6.9.10.12) ora de $\operatorname{Hobab}(\mathrm{Jz} 4,11)$ - se relaciona com o seu genro, favorecendo, dessa forma, o projeto liderado por este último. O mesmo vale para Séfora (Ex 4,25; 18,2), a mulher de Moisés (Ex 4,20; 18,2.5.6). Cf. FERNANDES, Leonardo Agostini. "Jetro reconhece o Senhor, Deus de Israel (Ex 18,1-12)”. In: Leonardo Agostini Fernandes; Matthias Grenzer, Êxodo 15,22-18,27. São Paulo: Paulinas, 2011, pp. 111-149.
} 
É justamente nesse sentido que o comportamento de Moisés favorece o encontro positivo entre pessoas de gêneros, países, culturas e crenças diferentes. Sua ação favorável a quem está sendo agredido reflete a ação do SENHOR, Deus de Israel, a qual é apresentada, de forma exemplar, na história do êxodo. Afinal, ao erguer-se, salvar e libertar das mãos do opressor aquele que está sendo oprimido e explorado, Moisés se torna semelhante a Deus e um modelo de comportamento digno a ser imitado por todos. Qualquer tipo de convivência mais promissora em relação ao futuro, pois, parece encontrar seus fundamentos exatamente nessa dinâmica de zelar pela liberdade de todos, em especial, daqueles que têm sua sobrevivência ameaçada por outros.

\section{Referências bibliográficas}

BAR-EFRAT, Shimon. Wie die Bibel erzählt. Alttestamentliche Texte als literarische Kunstwerke verstehen. Gütersloh: Gütersloher Verlagshaus, 2006.

DIETRICH, Walter; ARNET, Samuel (ed.). Konzise und Aktualisierte Ausgabe des Hebräischen und Aramäischen Lexikons zum Alten Testament (Koehler \& Baumgartner). Leiden: Brill, 2013.

DORMEYER, Detlev. Narratologie und Pragmatik. Ein Zwischenbericht. Biblische Zeitschrift 58 (2014), pp. 256-264.

ELLIGER, Karl; RUDOLPH, Wilhelm (eds.). Biblia Hebraica Stuttgartensia. 4. ed. Stuttgart: Deutsche Bibelgesellschaft, 1997.

FERNANDES, Leonardo Agostini. "Jetro reconhece o Senhor, Deus de Israel (Ex 18,1-12)". In: Leonardo Agostini Fernandes; Matthias Grenzer, Êxodo 15,22-18,27. São Paulo: Paulinas, 2011. pp. 111-149.

FISCHER, Georg; MARKL, Dominik. Das Buch Exodus. Stuttgart: Katholisches Bibelwerk, 2009.

FRITZ, Volkmar. Die Entstehung Israels im 12. und 11. Jahrhundert v. Chr. Stuttgart: Kohlhammer, 1996.

GRENZER, Matthias. "Decidido a defender o oprimido (Ex 2,11-15c)". In: Matthias Grenzer, O projeto do êxodo. 2. ed. São Paulo: Paulinas, 2007. 
KNAUF, Ernst Axel. Midian. Untersuchungen zur Geschichte Palästinas und Nordarabiens am Ende des 2. Jahrtausends v. Chr. Wiesbaden: Otto Harrassowitz, 1988.

MARGUERAT, Daniel; BOURQUIN, Yvan. Para ler as narrativas bíblicas. Iniciação à análise narrativa. São Paulo: Loyola, 2009.

UTZSCHNEIDER, Helmut; NITSCHE, StefanArk.ArbeitsbuchLiteraturwissenschaftliche Bibelauslegung. Eine Methodenlehre zur Exegese des Alten Testaments. 4. ed. Gütersloh: Gütersloher Verlagshaus, 2014.

UTZSCHNEIDER, Helmut; OSWALD, Wolfgang. Exodus 1-15. Stuttgart: Kohlhammer, 2013.

ZWICKEL, Wolfgang. Atlas bíblico. São Paulo: Paulinas, 2010.

Matthias Grenzer

Doutor em Teologia Bíblica e Mestre em História Professor na Pontifícia Universidade Católica de São Paulo

São Paulo / SP - Brasil E-mail: mgrenzer@pucsp.br

Recebido em: 23/10/14 Aprovado em: 29/10/14 